\title{
Health risk behaviors among male students in secondary schools in Erbil city
}

\section{Abstract}

Background and objective: Health behaviors and risk behaviors are often related to the community in a more complex pattern of behaviors associated with lifestyles. Risk behaviors include drinking alcohol, physical fighting, smoking, sexual intercourse and drug abuse. This study aimed to assess the rates of some health risk behaviors among male students of secondary schools in Erbil city and to find out associated factors with those risk behaviors.

Methods: A cross-sectional study was used. A self-administer questionnaire was used to collected data from December $17^{\text {th }}, 2012$ to July $17^{\text {th }}, 2013$ in 12 male secondary schools. 500 students were chosen randomly out of 11343 males' secondary school students.

Results: Smoking was the most common risk behavior among the students $(41.7 \%)$, followed by physical fighting (33.3\%), sexual intercourse (15.5\%), alcohol drinking $(6.6 \%)$, and the lowest risk behaviors comes from drug abuse $(2.7 \%)$. There was significant association between age and drug abuse which was more common among those $\geq 21$ years than those of younger age groups.

Conclusion: The highest health risk behavior among all male students in secondary schools in Erbil city was cigarette smoking. There was statistically significant association between age and drug abuse.

Keywords: Smoking, Drug abuse, Alcohol Drinking, Fighting, Sexual.

\section{Introduction}

Health behaviors are activities undertaken for the purpose of preventing or detecting disease or for improving health and well being or they are actions and habits that relate to health maintenance, to restoration and to health improvement. ${ }^{1}$ Health risk behaviors are any activity undertaken by people that affect on body or mind and increases risk or disease and injury and these risky behaviors might cluster together in to risky life style. ${ }^{2}$ Health behaviors and risk behaviors are often related in the community in a more complex pattern of behaviors related to lifestyles. Risk behaviors include drinking alcohol, violence, cigarette smoking, engaging in unprotected sexual intercourse, drug abuse, unhealthy diet and physical inactivity. These behaviors often begin during adolescence and contribute to the mortality and morbidity. ${ }^{3}$ Between ages 15 and 17, the average proportion of young people who reported weekly smoking and drinking increased by $17 \%$. Many of these young smokers will continue the habit throughout adulthood similarly An international survey had been done with $\mathrm{WHO}$ in Ireland in secondary schools showed that $28 \%$ were smokers, $28 \%$ were using alcohol, $18 \%$ abused drugs, $17 \%$ engaged in physical fighting and $27 \%$ had sexual intercourse. ${ }^{4}$ The findings of this study may impact school health program and health system policy to take care and intervention to reduce those unhealthy behaviors among adolescent students. To our knowledge there is no previous published study on health risk behaviors among students of secondary schools in

* Department of Community Nursing, College of Nursing, Hawler Medical University, Erbil, Iraq.

** Department of Nursing, College of Nursing, Hawler Medical University, Erbil, Iraq. 
Erbil city, there isn't enough data about prevalence of unhealthy behaviors among students in Erbil city and there is limited data in this particular field. The present study was designed to determine health risk behaviors in terms of alcohol use, drug abuse, sexual intercourse, physical fighting, and cigarette smoking and associated factors of these risk behaviors among male students of secondary school in Erbil city.

\section{Methods}

This cross sectional study was conducted in 12 out of 21 male secondary schools in Erbil city. 500 students were chosen randomly out of 11343 male secondary school students. The researchers choose the sample proportionately to the total size of students. The schools were chosen according to the municipality geographical distributions of Erbil city, which is classified into six municipality areas, and then, two schools from each municipality were randomly selected using stratified sampling. The sample size was calculated using the level of significance 95\%, 5\% degree of precision, and population size was 11343 of male secondary school students in grade 10,11, and 12). ${ }^{5}$ The sample selection of student's number for each school was conducted according to following formula:

$$
\text { Student sample }=\frac{\begin{array}{l}
\text { No. of student in specified school } \\
\times \text { sample size }
\end{array}}{\begin{array}{l}
\text { Total Number of students of } \\
\text { selected schools }
\end{array}}
$$

The sample distribution to six municipalities in Erbil city first started from center of city around of street of 60 meters, second started from road of Erbil-Mosel to road of Erbil-Shaqlawa, third started from road of Erbil-Saqlawa to road of Erbil-Koya, fourth started from road of Eskan to road of Erbil-Mahmur, fifth started from road of Erbil-Koya to road of Eskan street, sixth started from road of Erbil-Mahmur to road of Erbil-Mosel. In each municipality we selected two secondary schools randomly; in first municipality we selected Emadadin and Kurdistan secondary school, in second we selected Rozhinwe and Shex Mahmud, in third we selected Kurdaiaty and Halmat, in fourth we selected Gal and Sarwaran, in fifth we select Azadi and Hamreen, in sixth we selected Hawler and Ahmadixany. The study was conducted from the period of December $17^{\text {th }}, 2012$ to July $17^{\text {th }}, 2013$. The data were collected during the period of January $15^{\text {th }}, 2013$ to April $20^{\text {th }}, 2013$. A questionnaire was developed after extensive review of relevant literatures, which consisted of two parts. Part one was concerned with socio-demographic characteristics of students which included items such as age, grade, residence, occupation and education of parents. Part two was concerned with risk behaviors such as cigarette smoking, sexual intercourse, alcohol use, physical fighting and drug abuse with frequency and associated factors of these risk behaviors. The data were collected from students through using self-administration technique questionnaire. Students at grades 10, 11 and 12 were only included in the study. The data were collected in school halls and the students were provided with full explanation about the title, objectives and importance of the study. They were informed about how to fill in the questionnaire, and then they were advised to select the answer according to the real behavior. The orientation took about 15 minutes after the questionnaire forms had been distributed to them. The students were observed during answering the questions and if they had any inquiries about any points of the questionnaire, it was explained for them. The questionnaire was filled by students in the classroom in Kurdish language. Ethical consideration was a main principle of data collection. Permission has been taken from the Research Ethics Committee at the College of Nursing in Hawler Medical University. Permission to conduct this study was secured from the General Directorate of Education in Erbil. Data was prepared, 
organized and entered in to the computer. Statistical package for the social sciences (version 18) was used to analyze the data. Categorical variables were described through frequencies and percentages. The data were analyzed through the application of Chi-square test $\left(X^{2}\right)$ to determine the significance association between socio demographic data and fisher's exact test for low value.

\section{Results}

Table 1 shows that the commonest health risk behavior was smoking $(41.7 \%)$, followed by physical fighting (33.5\%), sexual intercourse $(15.5 \%)$, alcohol drinking (6.6\%), and the lowest risk factors was drug abuse (12.7\%). Table 2 shows that the majority of associated factor for smoking comes from friends (18\%), followed by stress, relatives, drinking tea/ coffee, pain, leisure and with drinking alcohol $(12 \%, 5.8 \%, 5.8 \%, 3.4 \%, 3.2 \%$ and $2 \%$, respectively) and the lowest risk factor comes from parents (1.6\%). Table 3 shows that the associated factors for physical fighting were related to having problem with classmate $(9.4 \%)$, followed by aggressive behaviors, family problems, girls and sexual intercourse $(6.8,4.8,2.1$ and 0.6 , respectively).

Table 1: Distribution of sample by health risk behaviors.

\begin{tabular}{lll}
\hline Risk behaviors & F & \% \\
\hline Smoking & 124 & 41.7 \\
Physical fighting & 100 & 33.5 \\
Total Sexual intercourse & 46 & 15.5 \\
Alcohol drinking & 20 & 6.6 \\
Drug abuse & 8 & 2.7 \\
Total & $\mathbf{2 9 6}$ & $\mathbf{1 0 0}$ \\
\hline
\end{tabular}

Table 2: Distribution of sample according to associated factors for smoking $(n=124)$.

\begin{tabular}{lll}
\hline Factors associated with smoking & F & \% \\
\hline With friends & 90 & 18 \\
With stress & 60 & 12 \\
With relative & 29 & 5.8 \\
With drinking tea/coffee & 29 & 5.8 \\
With pain & 17 & 3.4 \\
For leisure & 16 & 3.2 \\
With drinking alcohol & 10 & 2 \\
With parents & 13 & 1.6 \\
\hline
\end{tabular}

Table 3: Distribution of sample according to associated factors for physical fighting $(n=500)$

\begin{tabular}{lll}
\hline Factors' of physical fighting & F & \% \\
\hline Problem with classmate & 47 & 9.4 \\
Aggressive behaviors & 34 & 6.8 \\
Family problems & 24 & 4.8 \\
Girls & 6 & 2.1 \\
Sexual intercourse & 3 & 0.6 \\
\hline \hline
\end{tabular}


Table 4 shows that the associated factor for sex were related to having girlfriend $(6.4 \%)$, followed by sexual desire, internet use, peer, stress, having more money, lack commitment of religious, using mobile for chatting and going to clubs $(3 \%, 2.6 \%$, $2 \%, 1.8 \%, 1.6 \%, 1.6 \%, 1.2 \%$ and $0.6 \%$, respectively) and the lowest associated factor comes from alcohol drinking (0.4\%). Table 5 shows that the associated factors for drinking alcohol were related to smoking, felling sad, using internet, during picnic, friend problem, family problem, watching TV, sexual and cheapness of alcohol $(1.4 \%, 1.2,0.8,0.6$ and 0.4 , respectively). The associated risk factors for drug abuse were related to peer pressures $(1.2 \%)$, followed by girls $(1 \%)$, drug availability $(0.6 \%)$ and poverty and family problems $(0.2)$.

Table 4: Distribution of sample according to associated factors for sexual intercourse $(n=500)$

\begin{tabular}{lll}
\hline Associated risk factors of sexual intercourse & F & \% \\
\hline Having Girl Friend & 32 & 6.4 \\
Sexual Desire & 15 & 3 \\
Internet use & 13 & 2.6 \\
Peer Pressure & 10 & 2 \\
Stress & 9 & 1.8 \\
Having more money & 8 & 1.6 \\
Lack Commitment of Religious & 8 & 1.6 \\
Mobile & 6 & 1.2 \\
Going to club & 3 & 0.6 \\
Drinking alcohol & 2 & 0.4 \\
\hline
\end{tabular}

Table 5: Distribution of sample according to associated risk factors for alcohol drinking and drug abuse $(n=500)$

\begin{tabular}{lll}
\hline Associated factors & F & \% \\
\hline Factors of alcohol & & \\
Smoking & 7 & 1.4 \\
Felling sad & 7 & 1.4 \\
Internet & 6 & 1.2 \\
During the picnic & 4 & 0.8 \\
Friends problem & 4 & 0.8 \\
Watching TV. & 3 & 0.6 \\
Family problem & 2 & 0.4 \\
Sexual & 2 & 0.4 \\
Cheap & 2 & 0.4 \\
Factors for drug abuse & & \\
Peers pressure & 6 & 1.2 \\
Girls & 5 & 1 \\
Drug availability & 3 & 0.6 \\
Internet & 2 & 0.4 \\
Family problem & 1 & 0.2 \\
Poverty & 1 & 0.2 \\
\hline \hline
\end{tabular}


Table 6 shows that there was statistically high significant association between age of study sample with drug abuse $(P=0.001)$ with drug abuse being more common among the age group $\geq 21$ years than other age groups, while there was no statistically significant association between age and health risk behaviors such as cigarette smoking, sexual intercourse, alcohol drinking and physical fighting.

\section{Discussion}

The highest risk factors from all the risk behaviors which had been studied was smoking $(41.7 \%)$ and the others health risk behaviors were fighting, sexual intercourse, alcohol drinking and drug abuse. The current study is in agreement with a study done in Saudi-Arabia on 606 students which showed that the highest risk factor was smoking (29.8\%). The current findings also agree with the study done in west India by Mahraj $^{7}$ which showed that the highest (first) health risk behavior among high school students was smoking cigarette but it disagree with second priority of health risk behavior which was sexual intercourse, while physical fighting was the second priority of health risk behaviors in our study and this may be because of culture and religion diversity. The findings were also in disagreement with results of a study which was conducted in South Thailand by Sam-Angsri ${ }^{8}$ which showed that the most common health risk behaviors was alcohol drinking which represented $27.7 \%$, while in our study alcohol drinking comes before the last one. Cigarette smoking also comes in the second priority $(16.1 \%)$ in their study, but in our study cigarette smoking comes at the risk behaviors while drinking alcohol represented $6.6 \%$ of total risk behaviors. This result also disagrees with a study conducted in Scotland that showed that drinking alcohol had become as a second risk behavior. ${ }^{9}$ The current findings also disagree with the study done in US by Fox ${ }^{10}$ showed that the majority of health risk behaviors were alcohol drinking and the lowest health risk behaviors were smoking. While in our study the majority of health risk behaviors were smoking. In general, the prevalence of the majority of the risk factors in our schools were not high among students and may be mostly related to legal and ethical prohibition of the majority of these risk behaviors and also because of cultural beliefs of Kurdistan family against these risk behaviors. According to related factors of smoking, the result of present study reveals that the majority of reasons for smoking were because of friends, which represents $18 \%$. Our findings are in agreement with the results of a study conducted in Saudi-Arabia which showed that the most common reason given for cigarette smoking behavior was the

Table 6: Association between Age and Health risk behaviors.

\begin{tabular}{|c|c|c|c|c|c|c|c|}
\hline \multirow{3}{*}{ Risk behaviors } & \multicolumn{6}{|c|}{ Age group } & \multirow{3}{*}{$P$ value } \\
\hline & \multicolumn{2}{|c|}{$\begin{array}{l}\leq 17 \\
N=196\end{array}$} & \multicolumn{2}{|c|}{$\begin{array}{l}18-20 \\
N=252\end{array}$} & \multicolumn{2}{|c|}{$\begin{array}{l}\geq 21 \\
\mathrm{~N}=50\end{array}$} & \\
\hline & $\mathbf{F}$ & $\%$ & $\mathbf{F}$ & $\%$ & $\mathbf{F}$ & $\%$ & \\
\hline Cigarette smoking & 37 & 81.3 & 68 & 27 & 19 & 38 & 0.10 \\
\hline Sexual intercourse & 16 & 8.1 & 25 & 9.9 & 5 & 10 & 0.381 \\
\hline Alcohol drinking & 6 & 3 & 12 & 4.8 & 2 & 4 & 0.649 \\
\hline Physical fighting & 32 & 16.2 & 58 & 23 & 10 & 20 & 0.196 \\
\hline Drug abuse & 2 & 1 & 2 & 0.8 & 4 & 8 & 0.001 \\
\hline
\end{tabular}


influence of friends, representing $63.5 \%$. While it was disagreement with factors related to parents influence which it comes in their study as a second influence factors for smoking, while it comes as a last influence factor in our study which represent $(1.6 \%){ }^{6}$ In this study the parents was lowest associated factors for smoking and this could be due to the fact that in our culture smoking in front of our sons is unfavorable and the parents usually do not encourage their sons to smoke. In general, adolescents in our city may have positive attitude toward smoking, and smoking may not be a stigma in our social norms unlike alcohol and drug abuse. The result of the current study revealed that the most common associated factor of physical fighting was related to problems with classmate. This finding was in agreement with a study done in the Turkish high school students by Alikasifoglu ${ }^{11}$ which showed that the most common associated factors among high school students was fighting with friends (25\%). However, our findings in the present study disagree with a study done in Namibia by Rudatsikira ${ }^{12}$ which showed that drinking alcohol and drug abuse were highest associated factors with physical fighting, sexual intercourse and drug abuse. The present study revealed that the main associated factor for sexual intercourse was because of girl friends which represented $6.4 \%$ and others associated factors were sexual desire, internet use, peer, stress, having more money, lack commitment of religion, mobile, going to club, and drinking alcohol was the minimum reasons for sexual intercourse. These findings agree with project of campaign which done in Washington to prevent pregnancy which is part of center for disease control and prevention (CDC) which showed that most causes of sexual intercourse among adolescent were girl friends which have unhealthy behaviors (alcohol and drug use) and have sex with others risk behaviors (physical fighting, substances abuse). ${ }^{13}$ The current study showed that the main factors related to drinking alcohol were smoking and feeling sad. This result is supported by a WHO survey in Copenhagen in 2012 regarding associated factors of alcohol consumption which reported that alcohol use commonly occurs with other types of risk behavior such as tobacco, stress and illicit drug use and risky sexual. Other factors for drinking alcohol were family problem, marketing which increase relationship between adolescent exposures to alcohol marketing. ${ }^{14}$ Our findings were in disagreement with a study done in USA revealing that the two important associated factors for alcohol drinking were drug and smoking. Concerning associated factors with drug abuse, the main reasons for using drugs were because of peers pressures, girls, drug availability, internet use, family problem and poverty. Our findings agree with a study done in SaudiArabia $^{15}$ that showed the main associated factors of drug abuse were social peer pressure and family pressure. This finding disagreed with the result of a study done on 4903 students from Tabriz city in $\operatorname{Iran}^{16}$ that showed that the majority of associated factors for drug abuse were related to not living with the parents and smoking cigarette. The prevalence of drug abuse was considered low in our study, which is mostly related to legal prohibition of illicit drugs, social norms in Kurdistan families against substance abuse and parent's disapproval of drug abuse by adolescent. The current study revealed that there was significant association between drug abuse and age group, and there was no significant association between other health risk behaviors and age group. The current study was in agreement with a study from Cyprus ${ }^{17}$ that showed that there was significant association between drug abuse and age. The result of present study agrees with a study from Romania ${ }^{18}$ about the prevalence of drug abuse which showed that there are significantly increase of drug abuse. 


\section{Conclusion}

The commonest health risk behaviors among all male students in secondary schools in Erbil city were cigarette smoking, followed by physical fighting, sexual intercourse, alcohol drinking, and drug abuse. In relation to the associated factors for health risk behaviors, the result shows that the most common associated factors for smoking was because of friends, the reason for physical fighting was problem with classmate, for sexual intercourse was girl friends, and smoking for drinking alcohol, and peer pressure for drug abuse behavior. The study also shows that there was significant association between age and drug abuse.

\section{Conflicts of interest}

The authors report no conflicts of interest.

\section{References}

1. Conner M. Health behaviors, hand book of health behaviors research 2002, (3)1:87.

2. Adriana B, Catrinel C. Changing Health Risk Behaviors; a review of theory and evidence-based interventions in health, Journal of Cognitive and Behavioral Psychotherapies. 2007, 7(1) 45-67.

3. Kann L, Charles W. Warren, Janet L. Collins, Lloyd J. Health behaviors. J Adolescent Health, 2000;20 (2): 45.

4. Kelly C, Gavin A, Molcho M, Gabhainn S. The Irish Health Behavior in School-aged Children Study. Health Promotion Research Centre National University of Ireland, Galway .2012.

5. Araoye M, Research methodology with statistics for health and social science, 1E. Nathadex Publisher Irion 2003; 118-9.

6. Al-Damegh S, Saleh M., Al-Alfi M, and Al-Hoqail I. Cigarette smoking behavior among male secondary school students in the Central region of Saudi Arabia. Saudi Med J 2004; 25 (2): 215-9

7. Maharaj R.G, Nunes P, Renwick S. Health risk behaviors among adolescents in the English-speaking Caribbean: a review. J Child and Adolescent Psychiatry and Mental Health 2009; 3(10) 200-10

8. Sam-angsri $\mathrm{N}$, Assanangkornchai $S$, Pattanasattayawong $U$, Muekthong A. Health-Risk Behaviors among High-School Student in Southern Thailand, J Med Assoc Thai 2010; 93 (9): 1075- 2010.

9. Currie C, Levin K, Todd J National team Health behaviors in school age children survey in Scotland, 2008.
10. Fox $H$, McManus M, Arnold K, Significant Multiple risk behaviors Among U.S High school student, United State: National Alliance to Advance Adolescent Health 2010. Fact Sheet NO-8.

11. Alikasifoglu M, Ethmere G, Ercan O. Violent behavior among Turkish high school students and correlates of physical Fighting J. public health 2004; 2(14):173-4.

12. Rudatsikira E, Muula A iziy. Variables associated with physical fighting among US high-school students. Clinical Practice and Epidemiology in Mental Health 2008; 4(1):16.

13. Kirby D, Lepore G, Sexual risk and protect factors. The national campaign to prevent teen and unplanned pregnancy: United State , 2007.

14. WHO. Regional Office for Europe Fact shit report. Alcohol: why pay attention to this issue during adolescence 2012. Available from: http://www.euro.who.int/en/home.

15. Alibraim O, Elawad N, Misau Y, Shaikh T, Allam N. Drug dependence and psychotic symptoms: a retrospective study of adolescents who abuse drugs at Al-Amal Hospital. J Public Health in Africa 2012; 5(20):100-20.

16. Muhammad A, Nedjat S, Fakhari A, Yazdani K, Foroushani A. Substance Abuse in High School Students in Association with Socio-Demographic Variables in Northwes of Iran. Iranian J. Pub Health 2012;41(12):40-6.

17. Christophi z, Savvides E, Warren C., Demokritou P, Connolly G. Main determinants of cigarette smoking in youth based on the 2006. Prev Med 2006; 48(3), 232-6.

18. Lotrean L.M, Laza V, lonut C, Vries H. Assessment of health risk behaviors and their interrelationships among young people from two counties of Romania. J of public health 2010; 2(10) : 403-18. 